EGU2020-13582, updated on 21 Jun 2021

https://doi.org/10.5194/egusphere-egu2020-13582

EGU General Assembly 2020

(c) Author(s) 2021. This work is distributed under

the Creative Commons Attribution 4.0 License.

\title{
Development of a semi-distributed hydrological model on a tidal- affected river: application to the Adour catchment, France.
}

\author{
Valentin Mansanarez ${ }^{1,2}$, Guillaume Thirel ${ }^{2}$, Olivier Delaigue ${ }^{2}$, and Benoit Liquet $^{1}$ \\ 'Université de Pau et des Pays de I'Adour, E2S UPPA, CNRS, LMAP, Pau, France (valentin.mansanarez@inrae.fr) \\ ${ }^{2}$ Université Paris-Saclay, INRAE, UR HYCAR, 92160, Antony, France
}

Streamflow estimation from rain events is a delicate exercise. Watersheds are complex natural systems and their response to rainfall events is influenced by many factors. Hydrological rainfallrunoff modelling is traditionally used to understand those factors by predicting discharges from precipitation data. These models are simplified conceptualisations and thus still struggle when facing some particular processes linked to the catchment. Among those processes, the tide influence on river discharges is rarely accounted for in hydrological modelling when estimating streamflow series at river mouth areas. Instead, estimated streamflow series are sometimes corrected by coefficients to account for the tide effect.

In this presentation, we explored a semi-distributed hydrological model by adapting it to account for tidal-influence in the river mouth area. This model uses observed spatio-temporal rainfall and potential evapotranspiration databases to predict streamflow at gauged and ungauged locations within the catchment. The hydrological model is calibrated using streamflow observations and priors on parameter values to calibrate each model parameters of each sub-catchments. A drift procedure in the calibration process is used to ensure continuity in parameter values between upstream and downstream successive sub-catchments.

This novel approach was applied to a tidal-affected catchment: the Adour's catchment in southern France. Estimated results were compared to simulations without accounting for the tidal influence. Results from the new hydrological model were improved at tidal-affected locations of the catchment. They also show similar estimations in tidal-unaffected part of the catchment. 